When at the end of the granulous retruction of a large wound, the edges of the old epidermis are still at a distance of 20 or $25 \mathrm{~mm}$. the new cpidermis cannot spread on the granulations and the cicatrization of the wound comes to a standstill.

It seems that the time of the epidermization and its rate depends mainly on the dimensions of the wound. This point has been ascertained by several other sets of experiments.

By observing trapezoidal wounds it was found that the smaller side about $8 \mathrm{~mm}$. wille was completely epidermized while the larger side about $20 \mathrm{~mm}$. wide presented an epithelial bund of about $2 \mathrm{~mm}$. along the edges of the old epidermis. On irregular wounds the epidermization begins alwars on the points where the edges are closer to each other. In lozenge-shaped wounds the epidermization begins in the acute angles and the wound becomes an ellipse. On several linds of trapezoidal wounds it was always found that the epidermization begins sooner and spreads more quickly between the points which are separated by the shortest distance.

'Therefore, it appears that the law of reparation by epiclermization is absolutely different from the law of separation by granulous retraction. The rate of the epidermization is inversely proportional to the dimensions of the wound. It is very slow when the distance between the edges of the wound is more than 10 or 15 mm. 'The maximal activity of the epidermization seems to take place when the cicatrization is nearly complete, and when the edges of the new epithelium are very close to each other.

4. Cicalricial Period.-The dimensions of the scar can easily be measured when the edges of the old epidermis are stained with India ink, or when the aninial is black. It was found that the scar of a large wound is comparatively smaller than that of a small wound. On the same animal, two wounds of $66 \mathrm{~mm}$. and of 26 $\mathrm{mm}$. were observed. The $66 \mathrm{~mm}$. wound gave a scar of $22 \mathrm{~mm}$. and the $26 \mathrm{~mm}$. wound a scar of $13 \mathrm{~mm}$. 'The scar of the large wound was only one-third the size of the wound, while the sear of the small wound was onelualf the size of the wound. If the wound is still smaller, 10 or $12 \mathrm{~mm}$., the scar is almost the same size as the wound. This is the natural result of the law of granulous retraction.

The evolution of the scar is very slow and the ricatricial period of a wound very long. As soon as the epidermization is conıpleted, the distance between the points $A$ and $B$ of the edges of the old epidermis grows greater. The tracing shows a slight movement upward of the line representing the different values of the distance $A$ and $B$. The points $A$ and $B$ have a tendency to go back to their former position. 'This progressive enlargement of the scar lasts for a long time and its result should be a complete redintegration.

The mechanisms which are instrumental in the cicatrization of a wound are coordinated in such a way that the reparation is continuous and progressive. Nevertheless, the reparation presents phases of maximum and minimum activity during which the rate is higher or lower. During the quiescent period, the end of the period of granulous retraction and the beginning of the period of epidemization, the rate of the reparation is slow. It is maximum at the begrinning of the period of granulous retraction and at the end of the period of epidermization. The two mechanisms are adapted to the healing of small and middle-sized wounds, the width of which is not over $40 \mathrm{~mm}$. In a wound 30 or $40 \mathrm{~mm}$. in width or smaller, the retraction of the granulations is very efficient, since it can quickly bring the edges to a distance of 10 or $15 \mathrm{~mm}$. This distance is very favorable to the epidermization. Therefore, at the same time when the rate of reparation by granulation becomes very slow, the epidermization starts and the reparation goes on without interruption, although by a different mechanism. But if the wound is larger, 60 or $70 \mathrm{~mm}$, the retraction of the granulations cannot bring the edges to the minimum distance. They remain at a distance of about $20 \mathrm{~mm}$. and the repriation comes to a standstill because the epidermization cannot take place easily under these conditions. 'The mechanisms are very officient for the healing of the injuries to which the animals are exposed in their every-clay life. But they do not work as ratisfactorily for the larger wounds.

\section{VAPOR ANESTHESIA APPARATUS}

\section{JAMES T. GWATHMEY, M.D.} New YokK

In 1905 I first presented my apparatus for vanor anesthesia to the medical profession. At that time it seemed quite complicated. It consisted of three lottles connected by tubing, one of which was for ether, one for chloroform and the other being a bottle containing hot water or hot neutral oil for warming the vapor, and having a tube through which the vapor was delivered to the patient. Each bottle was provided with a stop-cock, and a mixture of chloroform and ether could he given. The ether bottle contained a drum for assisting in vaporizing the ether. I have perfected the different parts and

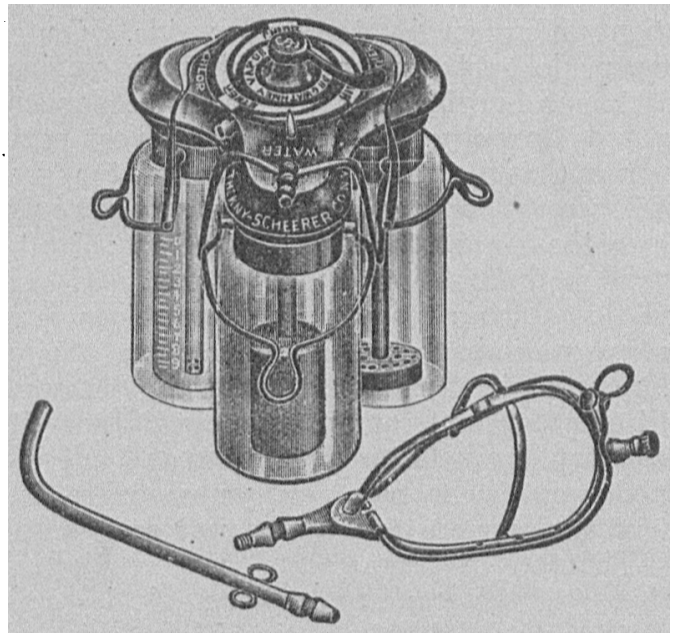

Iif. 1.-Thls shows the three bottles of the vaporizing apparatus, with the single stopeck. The figure at the right below shows the tubular frame of the mask through which the vapor passes to the rawze covering. The tube at the ieft below is used in dellvering the unesthetle in operations about the mouth or throut in which the mask canot be used.

now present a simplified apparatus consisting of three bottles with one stop-cock. The drum in the ether bottle has been modified (as suggested by Dr. Charles F. Boys, Kalamazoo, Mich.), so that it now vaporizes all of the ether, and it does not necessitute refilling the bottle as often as before. A small bottle holding 10 drams of chloroform has also been placed within the chloroform bottle. This is enough chloroform for a long operation. 'The end of the tube in the chloroform hottle has been closed and a number of ninhole perforations made at the bottom of this tube, so that it is impossible to waste 1l:e chloroform as the air passes through. The last improve- 
ment has been to place around the mask a rubber covering which confines the vapor and assists in making the anesthetic more manageable.

If one ounce of the oil of bergamot or terpineol is placed with 3 ounces of water in the hot-water bottle, the odor of ether or chloroform will be so disguised that the patient will be unable to distinguish when the anesthetic is turned on, and consequently no resistance or asphyxial symptoms present themselves in going under the anesthetic. 'Then again, it is much pleasanter for the surgeon, nurses and others in the room to smell the oil of bergamot or terpineol than to be constantly inhaling the odors of ether and chloroliorm.

At any time the anesthetist can give either chloroform or ether, or any combination of the two, by simply turning the single stop-cock, the change being made in less than a fraction of a second, all of the vapor passing through the third bottle, ustually filled with hot water, and terpineol or a hot neutral oil. Enquestionably a smaller amount of anesthetic is used with this apparatus, or with rome similar apparatus, than with any ather method now known. It has been used constantly in some of our largest hospitals since 1905, with increasingly gratifying results in the following particulars:

1. A smaller amount of anestlietic is nsed. In a chloroform anesthesia, in which ether was contra-indicated on areount of an uleer in the stomach, I used 2 drams of chloroform for a
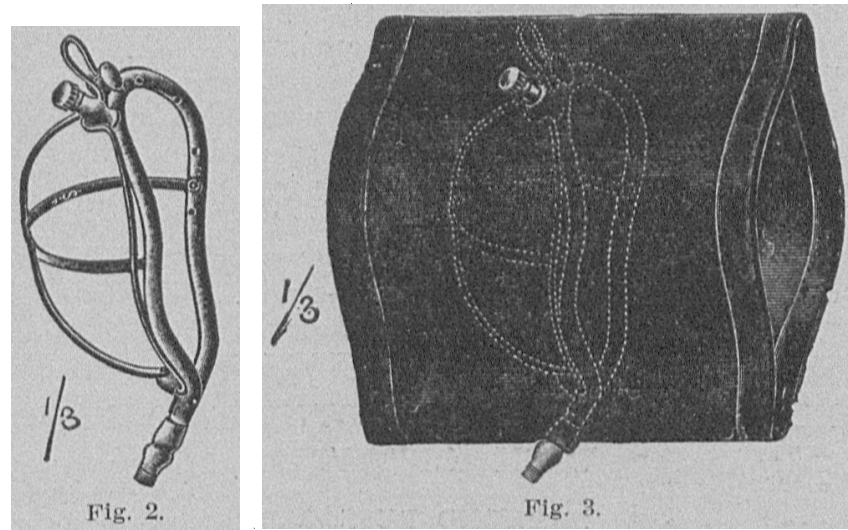

Wigr. 2.-Illustration of mask one-\{h]rd sizr.

lik. - - Illustration of rubber covering for misk, which helps to prevent cooling und waste of the anestbetle.

twenty-five-minute operution. Two or three ounces of ether with one to two drams of chloroform per hour is the usial unount used.

2. The technic can be acquired with less danger to the jatient than with uny other anesthetizing method. In getting the patient entirely under, with this apparatus alone, excitement is usually absent, or so slight that it is unobjectionable

3. In over 90 per cent. of the cases umpleasant after-effects are entirely absent.

4. A continual narcosis is always nuintained, as we know exacly what por cent. the patient is getting at all times, and in addition the gradations are easily and readily mado by moving the one lever according to the degree of nurcosis demanded by the operation. An intermitting nurcosis, which is wrong in principle, is thus avoided. It is especiully indi cated for rose and throat operations, and is the appuratus for mastoid operations. The anesthetist cun maintain primary anestlesia, moving backward and forward between what is commonly known as the second und third degree of anesthesia, without once arousing the dangerous vomiting center. All of the vapor, being warmed, is more respiruble, reducing the after effects and increasing its safety as regards life. With this attenuated vapor, an infant three days oll can be safely anesthetized and an alcoholic can be easily kcpt under, after reaching the surgical stage. Al] patients can be uarcotized within five minutes, and with this wasmed vapor, the kidneys, hait and lungs are never seriously affected.

In order to discover the value of passing this valır through hot water, the following tests were made by 1)r. Chas. Baskerville, professor of chemistry, College of the City of New York:

1. Pure oxygen was passed for seventeen mimutes through 4 ounces of anesthetic ether, the resulting mixture pussing through the hot-water bottle with the water at $60 \mathrm{C}$. The: first 10 c.c. of distillate were collected. The ether used in this test had given a pronounced aldehyd reaction when allowed 10 stand over potassium hydroxid for six hours, but the distillate obtained in the above experiment gave only a slight rexponse.

2. An experiment was made, using water at 40 (. und applying external heat to the water-container mufficient fos insure vaporization of the ether. The ether distillate obtuined under these conditions, gave a negative reaction for aldehyd. It will appenr from these results that the aldehyd is removol when ether vapor is passed through water in the neighborliood of $40 \mathrm{C}$., and that the aldehyd content of the ether passinl through is considerably diminished and its toxic value is especially lessened, when the water is kept at a temperature in the neighborlood of $60 . \mathrm{C}$.

The vapor apparatus may be used in combination with a vacuun water pump, similar to the one reed by dentists for removing blood and secretions from the mouth and throat in operations about those parts, in which it is necessary to remove the mask. 'The anesthetic vapor' in this instance is administered through a metal tube attached to the delivery tube of the apparatus. I have improved the pump by the addition of an adjustable connection that can be attached to any hydrant of tap.

124 East Sixteenth Street.

\section{EYE-S'TRAIN A CAUSE OF EXOPH'THALMIC GOI'TER}

\section{GEORGE M. (GOULD, M.D. A ND}

\section{A. C. DURANID, MI.D.}

ITHACA, N. Y.

Exophthalmic :goiter, it is sajd, is. or may be indicated by four symptoms, tachyendia, exophthnlmos, goiter, and tremor. Thachycardia is usually held to be the early, leading, or primary srmptom, the of her three trailing off in relative unimportance. Indeed, any one or two, perhaps three, of the four may be absent, and yet the real norbific Proteus be present, concealed and yet pathogenic by means of the one or two remaining.

Pathology of a serious or lational standing has really nothing to offer as to the cause and mature of the diseaso. 'The oculists have kindly shoved the problem off into the far country labeled "ductless glands," and it has been quizzically suggested that the exophthalmic principality of the quadruple-crowned and loosely joined grandduchies, owes all its independence to a wondrous little, and little wondrous, "muscle of Miiller," situated at the orbital fissure. How it is possible for these tiny fibers by contraction to produce the distortion of a huge, or of any degree, of exophthalmos, with its attendunt signs and symptoms, what may be the physiologic function of this muscle in the first place, and consequently what is its morbid function, how the thyroid secretion can execute such a task-all these, and more, raise the corner's of the mouth of the genuine scientist. Indeed, the illogricalities of the symptom-complex and of the group-nume 